\title{
Desinfección bacteriana de aguas residuales utilizando cavitación hidrodinámica a través de un tubo Venturi
}

\author{
Esteban Lafuente, Héctor López \\ Departamento de Ciencias de la Energía y Mecánica, Universidad de las Fuerzas Armadas-ESPE \\ lafuenteesteban@hotmail.com, hector-andy@hotmail.com
}

\begin{abstract}
Resumen-Este estudio muestra un proceso de desinfección bacteriana de las aguas contaminadas del Río Santa Clara utilizando un método de cavitación hidrodinámica. Se utilizó un circuito de prueba cerrado con posibilidad de controlar la velocidad de flujo y la presión estática. El comportamiento de la cavitación ha sido capturado por un sensor de temperatura, tres sensores de presión y una cámara de alta velocidad. El resultado del experimento muestra que la cavitación hidrodinámica es un método físico, energéticamente eficiente y, por lo tanto, puede considerarse como una técnica potencial para un esquema de tratamiento de agua a gran escala. Así como, que luego de tratar el agua durante el mismo tiempo a distintas presiones de descarga se evidencia que cuando la presión de descarga aumenta, el grado de eficiencia de desinfección también aumenta.
\end{abstract}

Palabras Claves-Desinfección bacteriana, cavitación hidrodinámica.

Abstract-This paper shows a bacterial disinfection process of the polluted waters of the Santa Clara River using a hydrodynamic cavitation method. A closed test circuit was used with the possibility of controlling flow velocity and the static pressure. A temperature sensor, three pressure sensors and a high-speed camera have captured the behavior of the cavitation. The result of the study shows that hydrodynamic cavitation is a physical, energy efficient method and, therefore, can be seen as a potential capability for a large-scale water treatment scheme. As well as, after treating the water during the same time at different discharge pressures it is evident that when the discharge pressure increases, the degree of disinfection efficiency also increases.

Keywords - Bacterial disinfection, hydrodynamic cavitation.

\section{INTRODUCCIÓN}

Reynolds (1894) es el primer investigador que demuestra el fenómeno de cavitación realizando experimentos en un tubo Venturi y verificando que se forman nubes de burbujas en las proximidades de la garganta, demostrando que el agua puede hervir a temperatura ambiente en un tubo mediante una caída de presión [1]. A partir de Reynolds la cavitación se ha tornado en un tema de investigación muy fuerte asociándolo como un efecto negativo en el funcionamiento apropiado de un sistema hidráulico.

En las últimas décadas, se han hecho esfuerzos concentrados por investigadores alrededor del mundo para provechar los espectaculares efectos de la cavitación hidrodinámica en transformaciones físico/químicas. Jyoti y Pandit (2001) investigaron la aplicación de la cavitación para la desinfección de agua de pozo en diferentes reactores de cavitación utilizando una placa orificio y compararon su eficacia con el tipo de reactor ultrasónico, obteniendo como resultado que la cavitación hidrodinámica se puede utilizar para un mayor desarrollo frente a la cavitación ultrasónica que requiere más energía y por lo tanto un costo más elevado al momento de utilizarlo [2]. Arrojo et al. (2005) ha investigado el efecto de la cavitación hidrodinámica como un procesos de oxidación avanzada utilizando diferentes diseños de cámara de cavitación como placas orificio, tubos Venturi y placas de impacto, llegando a determinar que debido a las condiciones de presión y temperatura extremas dentro de las burbujas, el agua se disocia en radicales $\mathrm{H}$ y $\mathrm{OH}$, provocando un desinfectante muy fuerte que actúa de manera irremediable en los componentes celulares [3].

Eva Fathul Karamah et al. (2013) realizó un estudio sobre la tasa de inactivación de Escherichia coli, una de las bacterias más comunes presentes frecuentemente en el intestino distal de los organismos de sangre caliente, en un reactor de cavitación hidrodinámica utilizando un Tubo Venturi y una placa orificio [4].

Uno de los problemas más grande que presenta el Ecuador, es la contaminación bacteriana de los ríos a causa de la descarga de aguas residuales domésticas no tratadas mediante sistemas sanitarios y por descargas directas de aguas industriales que pueden provocar en su mayoría enfermedades del tracto digestivo humano [9].

El propósito de este artículo implica un estudio experimental de cavitación hidrodinámica en una tobera axisimétrica convergente-divergente, y cuantificar el poder bactericida en la desinfección de las aguas contaminadas del río Santa Clara en Ecuador.

\section{MÉTODO}

Se utilizó un circuito de prueba cerrado con posibilidad de controlar la velocidad de flujo y la presión estática como indica la Fig. 1. Los diferentes regímenes de cavitación en un tubo Venturi se generan cambiando sistemáticamente la presión estática aguas arriba a través de una válvula de compuerta. El comportamiento de la cavitación ha sido capturado por tres sensores de presión en el tubo Venturi, un sensor de temperatura y una cámara de alta velocidad (Phantom V2512). La bomba utilizada para la experimentación es una bomba centrífuga de 2HP con una capacidad máxima de $100 \mathrm{lpm}$. Todos los elementos del circuito se encuentran conectados mediante tubería PVC y mangueras de alta presión para producir la recirculación del flujo. 


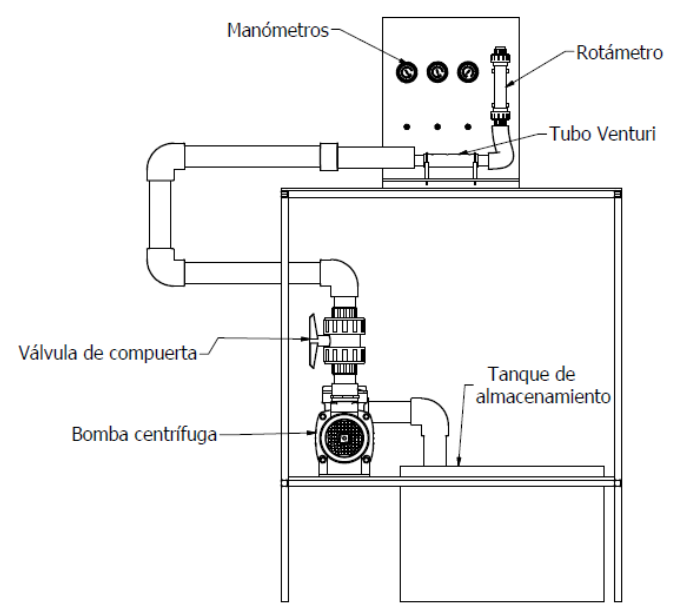

Fig. 1. Banco de pruebas para cavitación hidrodinámica

\section{A. Diseño del tubo Venturi}

Los Venturis son dispositivos que tienen el papel principal del control del caudal másico. El tubo convergente es un dispositivo eficaz para convertir la cabeza de presión en velocidad, mientras que el tubo divergente convierte la cabeza de velocidad a la cabeza de presión [6].

El tubo Venturi está hecho de polimetilmetacrilato, que es más conocido como perspex o acrílico. La propiedad más importante de este material es la alta transmisión de luz, que brinda la capacidad de acceso óptico a la dinámica de cavitación. Según la investigación realizada por Arrojo et al. (2005), presenta que los mejores ángulos de divergencia para que un tubo Venturi tenga un cambio de presión adecuado son los ángulos entre $10^{\circ}$ y $30^{\circ}$. Para nuestro diseño se optó por el ángulo de $20^{\circ}$ que presenta el mejor cambio de presión.

\section{B. Procedimiento del experimento de desinfección de agua residual}

El río Santa Clara presenta un mal olor, aguas grises y mala apariencia por la cantidad de desechos eliminados al río a causa de los hogares aledaños al sector, como indica la Fig. 2. Por este motivo este río presenta las condiciones de contaminación adecuada para el tratamiento.

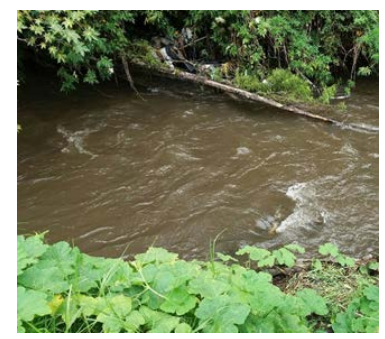

Fig. 2. Mala apariencia del Río Santa Clara.

El procedimiento se lleva a cabo inmediatamente después de recolectada el agua, sin dejar pasar más de 30 minutos en su transporte y colocación en el equipo de cavitación. Se contó con frascos esterilizados para la toma de muestras, realizando la primera toma antes de arrancar el equipo. Posteriormente se enciende la bomba y se programa a una medición de caudal y presión fija, lo que viene asociado con una intensidad de cavitación, dejándolo en marcha durante 65 minutos.

Para el análisis de bacterias se preparó el medio de cultivo para el crecimiento de las bacterias con "Standard Methods Agar”, el cual se repartió en 21 cajas Petri esterilizadas. Con el uso de una micropipeta se tomó 10 microlitros de cada muestra repartiendo uniformemente en cada medio; realizando 2 cultivos para cada tiempo y poder analizar los datos que se van a obtener.

Una vez finalizado el procedimiento de cultivo, se sella las cajas con parafilm y se las coloca en la incubadora a $37^{\circ}$ $\mathrm{C}$, proporcionando las condiciones propicias para el crecimiento de las bacterias. Al cabo de $15 \pm 3$ horas se procedió a observar los cultivos y contabilizar el número de unidades formadoras de colonias (UFC) que se han producido.

\section{ANÁLISIS DE RESULtAdOS}

\section{A. Porcentaje de desinfección en función del tiempo utilizando cavitación hidrodinámica.}

Se estudió la aplicación de desinfección de agua con la finalidad de caracterizar el fenómeno de cavitación verificando su efectividad para destruir bacterias y buscando relacionar la intensidad de la cavitación como función bactericida. Para esto, se realizó dos experimentos independientes, a distintas presiones de descarga, 2 bar y 3 bar. El efecto de la presión (asociada a la intensidad de cavitación) sobre la desinfección con cavitación hidrodinámica es mostrado en la Fig. 3 la cual muestra el porcentaje de desinfección versus el tiempo de tratamiento.

Dado que la concentración inicial de bacterias era diferente para cada experimento se decidió representar el porcentaje aniquilado de la población de bacterias y no el número de unidades formadoras de colonias como variable de visualización.

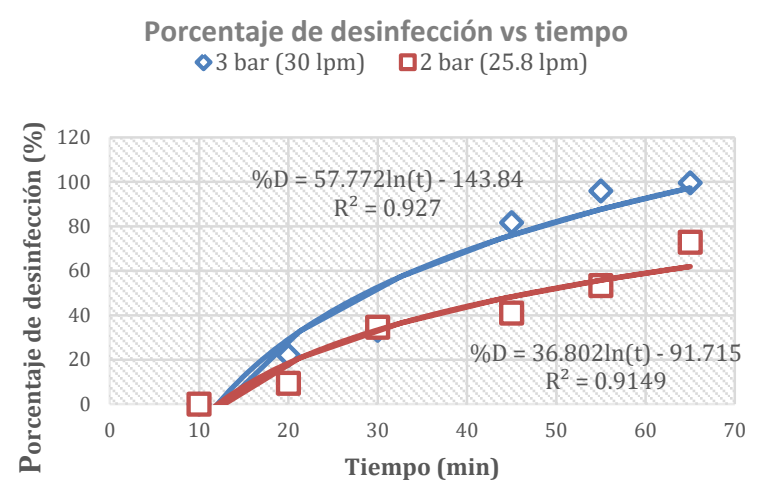

Fig. 3. Porcentaje de desinfección usando cavitación hidrodinámica.

En base a los resultados obtenidos se puede realizar las siguientes observaciones.

Luego de tratar el agua durante el mismo tiempo a distintas presiones de descarga se evidencia que cuando la presión de descarga aumenta, el grado de eficiencia de desinfección también aumenta. Así, la Fig. 3 muestra que transcurrieron 65 minutos para disminuir el recuento en un $72.8 \%$ a 2 bar, mientras que para el mismo tiempo se alcanzó una disminución del 99.5\% trabajando el sistema a una presión de descarga de 3 bar. Por tanto, se puede decir que, para lograr un cierto nivel de desinfección, el tiempo requerido será menor cuando se opere con presiones más altas. 
Al aumentar la presión de descarga, la caída de presión en la garganta es mayor, lo que provoca una mayor duración en cada ciclo de cavitación de 0.00267 segundos para 2 bar y 0.00303 segundos para 3 bar, logrando que las cavidades crezcan más. Las mismas que posteriormente generarán un mayor trabajo de compresión y producirán un colapso más violento, liberando mayor cantidad de energía [6].

\section{B. Proceso de Tinción Gram realizado a las bacterias.}

Al observar los resultados del proceso de la tinción de Gram realizado al agua antes de someterla al tratamiento como indica la Fig. 4 (izquierda) se puede evidenciar una gran presencia de bacterias Gram negativas (color rosa) y Gram positivas (color púrpura) con distintas formas como cocos, bacilos, y espirilos. Comparando con la tinción de Gram realizada a las colonias sobrevivientes después del proceso de desinfección presentado en la Fig. 4 (derecha), se evidencia la presencia de bacterias Gram positivas únicamente, las cuales son más resistentes por poseer una pared celular de peptidoglucano más gruesa. Por lo que, la desinfección con cavitación no es totalmente efectiva contra bacterias Gram positivas.
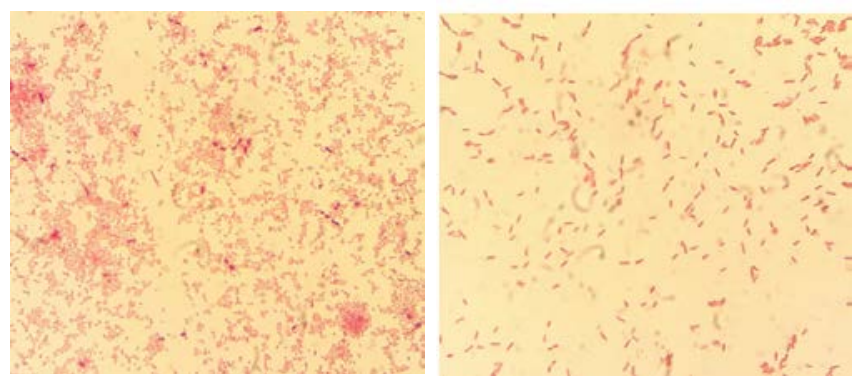

Fig. 4. Tinción de Gram para la población inicial y final de bacterias respectivamente.

$\mathrm{Al}$ realizar el reconteo del resultado final en el tratamiento con 2 bar de presión se presentó una gran cantidad de UFC de dimensiones muy pequeñas pero perceptibles a simple vista, lo cual imposibilitó el conteo y mostró un comportamiento fuera de la tendencia. A estas colonias se les realizo una tinción de Gram que se muestra en la Fig. 5, en la cual se observó la presencia de endosporas probablemente desarrolladas por las bacterias durante el tratamiento, al encontrarse en una situación de estrés y sentirse amenazadas por los efectos de la presión, temperatura, radicales y demás mecanismos de destrucción presentes en la cavitación.

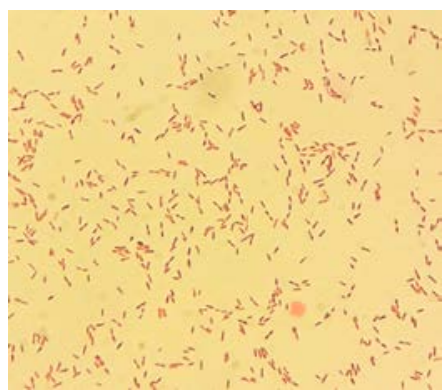

Fig. 5. Esporangios teñidos de mayor intensidad en su interior por la presencia de endosporas.

\section{Métodos de eliminación de bacterias.}

El mecanismo de desinfección de bacterias usando cavitación hidrodinámica es una combinación de efecto mecánico, efecto químico y efecto de calor [8].

El efecto mecánico en la alteración de las células bacteriana tiene varios mecanismos mediante la formación de remolinos, vórtices y flujos reentrantes a diferentes escalas de tamaño. Estos fenómenos producen una diferencia de presión en las paredes de las células. Cuando esto excede la resistencia de la pared celular, la célula se rompe [8]. Los efectos mecánicos fueron observados a través de una cámara de alta velocidad como indica la Fig. 6 donde se presenta un ciclo de las cavidades que se puede resumir por lo siguiente: inicio de la cavitación, desarrollo de las cavidades, desprendimiento con advección y un colapso total aguas abajo generando puntos calientes localizados (condición de temperatura y presión muy altas localmente) [11].

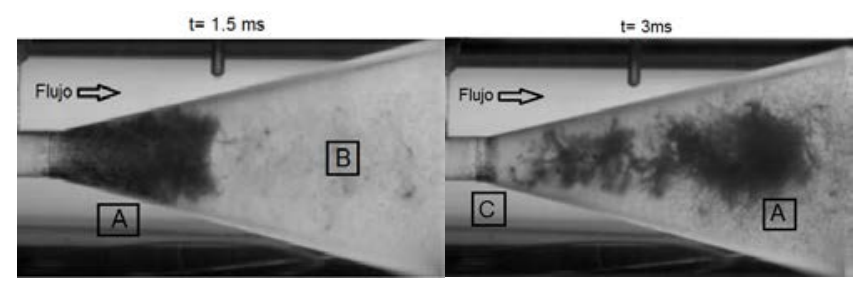

Fig. 6. Ciclo de las cavidades en cavitación hidrodinámica.

El efecto químico incluye el ataque del radical hidroxilo $(\mathrm{OH})$ y la disrupción física de las membranas celulares. Según Medina el al. (2008) el radical hidroxilo $\mathrm{OH}$ es altamente reactivo y muy tóxico para los microorganismos, repercutiendo de manera irremediable en la cadena de ADN [12].

\section{Eficiencia energética}

Con la finalidad de verificar la viabilidad económica del proceso de cavitación, se calcula la tasa de consumo de energía para un grado específico de desinfección. Este método se basa únicamente en el consumo de energía eléctrica, como indica la Tabla I.

TABLA I

CÁLCULOS ENERGÉTICOS DE VIABILIDAD ECONÓMICA DEL PROCESO

\begin{tabular}{|c|c|}
\hline "Tiempo del tratamiento: & 65 minutos (3900 s) \\
\hline Volumen utilizado: & $15000[\mathrm{ml}]$ \\
\hline Consumo eléctrico: & 714 [W] \\
\hline $\mathrm{UFC} / \mathrm{ml}$ inicial: & 19600 \\
\hline $\begin{array}{l}\text { Al cabo de } 65 \text { min, } \\
\text { UFC/ml: }\end{array}$ & 100 \\
\hline UFC eliminadas en $65 \mathrm{~min}$ & 19500 \\
\hline $\begin{array}{l}\text { UFC eliminadas/W de } \\
\text { consumo eléctrico: }\end{array}$ & $\frac{19500 U F C / m l}{648 W}=30.1 \frac{U F C / m l}{W}$ \\
\hline $\begin{array}{l}\text { UFC eliminadas/J de } \\
\text { consumo eléctrico: }\end{array}$ & $\begin{array}{l}30.1 \frac{U F C * s}{m l * J} * \frac{15000 \mathrm{ml}}{3900 \mathrm{~s}} \\
=115.77 \frac{U F C}{J}\end{array}$ \\
\hline
\end{tabular}

Adicionalmente se calcula el costo de la energía eléctrica que se consumió al aplicar el tratamiento a 15 litros de agua durante los 65 minutos. Usando la tarifa eléctrica industrial en Ecuador de 9,1 centavos el kilovatio hora [5] se obtiene un costo de 7.04 centavos de dólar por el tratamiento a 3 bar 
de presión de descarga. Por lo que se evidencia la factibilidad económica de este proceso como desinfectante físico en comparación con la cloración, considerado el método más común para desinfección de bacteria que presenta desventajas peligrosas para la salud humana, incluida la formación de subproductos de desinfección cancerígenos y la aparición de problemas de sabor y olor en el agua procesada [10]. Sin embargo, su uso en Ecuador se debe a que esta técnica es más barata en dos órdenes de magnitud en comparación con el método físico de cavitación descrito en este artículo [2].

\section{CONCLUSIONES}

La cavitación parece ser una técnica prometedora para la desinfección del agua. Al ser un método no químico, su uso no permite la formación de subproductos tóxicos, como es el caso de los tratamientos químicos que utilizan cloro. Es un proceso energéticamente eficiente y viable, por lo tanto, puede considerarse como una técnica potencial para un esquema de tratamiento de agua a gran escala. Se comprobó la aplicabilidad del fenómeno de cavitación hidrodinámica como un proceso bactericida, al tomar muestras del río Santa Clara y someterlas al tratamiento durante 65 minutos a distintas presiones. Adicionalmente se identificó que para una mayor presión de descarga el proceso mejora su eficiencia; así, para una presión de descarga de 2 bar se alcanzó una desinfección del 72.8\%, mientras que para una presión de 3 bar se alcanzó el 99.5\% de desinfección. Por otro lado, cabe recalcar que la cavitación no provee una protección residual, por lo que una mínima cantidad de bacterias viables pueden producir un rebrote de población.

\section{AGRADECIMIENTOS}

Agradecemos a la empresa ABAXFEM S.A. por el apoyo financiero e intelectual brindado para esta investigación, de manera especial al Ing. Edgardo Fernández representante de la empresa.

\section{REFERENCIAS}

[1] W. Hogendoorn, "Experimental investigation of cavitation regimes in a converging-diverging nozzle", Delft University of Technology, Países Bajos, 2017.

[2] K. Jyoti y A. Pandit, "Water disinfection by acoustic and hydrodynamic cavitation”, Biochemical Engineering, 2001. Available: https://doi.org/10.1016/S1369-703X(00)00128-5

[3] Y. Benito y S. Arrojo, "Hydrodynamic Cavitation as a low-cost AOP for wastewater treatment”, Water Resources Management III, pp. 495-503, 2005

[4] E. Karamah y I. Sunarko, "Disinfection of bacteria Escherichia coli using hydrodinamic cavitation”, International Journal of Technology, vol. Available: http://dx.doi.org/10.14716/ijtech.v5i1.116, p. 209-216, 2013.

[5] Tapia, E. (24 de Octubre de 2017). La tarifa de energía eléctrica para industrias se revisa. El Comercio.

[6] J. P. Franc, The Rayleigh-Plesset equation: a simple and powerful tool to undestand various aspects of cavitation, Francia: University of Grenoble, 2006.

[7] Niedźwiedzka, A., \& Sobieski, W. (2016). Analytical Analysis of cavitating flow in venturi tube on the basis of experimental data. Technical Sciences, 215-229

[8] Save, S.S., Pandit, A.B., Joshi, J.B., 1997. Use of Hydrodynamic Cavitation for Large Scale Microbial Cell Disruption. Trans IchemE, Volume 75 Part C

[9] R.-T. Lilia y M.-N. Jorge, "Bacterial Pollution in River Waters and Gastrointestinal Diseases”, Environmental Research and Public Health, vol. 14, pp. 1-11, 2017.
[10] Mezule, L,S., Tsyfansky, V., Yakushevich, Juhna, T., 2009. A Simple Technique for Water Disinfection with Hydrodynamic Cavitation: Effect on Survival of Escherichia coli. Desalination, Volume 248, pp. 152-159

[11] Gogate, P., \& Pandit, A. (2001). Hydrodynamic cavitation reactors: A state of the art review. Reviews in Chemical Engineering, 1-85.

[12] Medina, L., \& Valencia, L. (2008). Evaluación de la eficacia de un desinfectante de alto nivel, a base de peróxido de hidrógeno, empleado en la esterilización de dispositivos e instrumentos hospitalarios. Bogotá. 